\title{
Telemonitoring for Independently Living Elderly: Inventory of Needs \& Requirements
}

\author{
Sander Bakkes, Richard Morsch, and Ben Kröse \\ CREATE-IT Applied Research, Amsterdam University of Applied Sciences (HvA) \\ Amsterdam, The Netherlands \\ s.c.j.bakkes@hva.nl,r.s.morsch@student.uva.nl,b.j.a.krose@hva.nl
}

\begin{abstract}
In this paper we investigate the precise focus required of a telemonitoring system for the domain of independently living elderly. Particularly, we investigate (1) the needs of telemonitoring for this particular domain, and (2) the requirements for such a telemonitoring system. For our investigation, we performed an extensive study of the literature, as well as performed interviews with 36 individuals active in the field. As a result, we established numerous needs to be considered, being foremost information need on safety, with regard to care response on emergencies (e.g., falling incidents, wandering), as well information need on dependence on care, with regard to inactivity, self-neglect and loneliness. Subsequently, we established numerous requirements to be addressed, being foremost the use of non-wearable sensors, unobtrusiveness, durability, reliability, privacy, and ubiquitousness. In our discussion of the requirements, we detailed specifically the topics of focus, functionality, and form of a telemonitoring system for this domain.

Index Terms - Telemonitoring, independently living elderly, needs \& requirements study.
\end{abstract}

\section{INTRODUCTION}

Telemonitoring concerns the use of information technology to monitor people at a distance. Literature suggests that the most promising application for telemonitoring is for chronic illnesses such as cardiopulmonary disease, asthma, and heart failure [1]. Moreover, telemonitoring is regarded as a way of responding to the new needs of home care in an ageing population [2], [1]. That is, the population of people aged 80 or over is projected to increase more than five times by the year 2050 [3]. As people age, they depend more heavily upon outside support for health assessment and medical care. Currently, health-care infrastructure is not adequately adjusted to meet the growing needs of an increasingly older population [4], [5], [6].

In the research discussed in this paper, we focus particularly on telemonitoring for the independently living elderly. Demographic changes and social and political influences are leading to a greater number of elderly people living alone [7]. Particularly this group is prone to unscheduled and costly hospitalisation that would have been avoidable should accurate assessments on the client's health and wellbeing have been available. Though numerous systems for telemonitoring have been developed [1], the precise focus required of a telemonitoring system for the domain of independently living elderly remains unclear. That is, there is a demand for an overview with respect to (1) the needs of telemonitoring for this particular domain, and (2) the requirements for such a telemonitoring system. The present paper contributes in this regard by providing an overview of needs and requirements on the basis of an extensive literature study and interviews with distinct target groups.

The outline of the paper is as follows. We first give an extensive overview of related work in the field of telemonitoring (Section II). Subsequently, we describe our approach to establishing an inventory of the needs (Section III). Next, on the basis of the determined needs, we set the requirements for a telemonitoring system for independently living elderly (Section IV). Finally, we provide conclusions and describe future work (Section V).

\section{RELATED WORK}

In our overview of related work we first discuss approaches to telemonitoring that we consider relevant for the domain of independently living elderly. We distinguish between approaches to monitor vital signs (e.g., heart rate) (Subsection II-A), to detect non-medical emergencies (e.g., falling incidents) (Subsection II-B), and to monitor activities of daily living (e.g., feeding) (Subsection II-C). Subsequently, we report on related work with regard to the needs and the requirements for a telemonitoring systems for independently living elderly (Subsection II-D).

\section{A. Monitoring of vital signs}

Literature has demonstrated that many vital signs can be telemonitored successfully. A substantial focus of telemonitoring systems for vital signs lies on measuring cardiovascular activity. Research has been performed into monitoring heart rate [8], [9], fetal heart rate [10], blood pressure [11], [12], [9], [8], ECG [13], [14], [8], [15], [9], pacemaker parameters [15], [16], and stethoscopy [17]. Another strong focus lies on telemonitoring systems to measure aspects of metabolism. For instance, systems exist to measure basal metabolic rate [18], blood glucose [19], blood lactate [20], blood ethanol [20], physical exercise [19], and body temperature [20], [8].

In addition, hematologic telemonitoring systems have been developped [21], as well as respiratory system to measure e.g., pulse oximetry [9], spirometry [22], [23] and respiratory rate [8], [14]. Neurologic systems that measure and transfer EEG [24] and EMG [25] have been developed, as well as systems to measure intravesical urological pressure [26]. 


\section{B. Detecting non-medical emergencies}

Information provided by a telemonitoring system may be utilised for the task of detecting automatically emergency situations. In this paper, with emergency situations we refer to situations (1) which require immediate care, (2) of which the occurrence cannot be anticipated straightforwardly, and (3) of which the required care does not concern specialist medical knowledge (i.e., as opposed to the occurrence of a heart attack). Common instances of such emergency situations, which form a major health hazard, are falling incidents and wandering [27].

With regard to detecting falling incidents, a study by Horton [28] established that telemonitoring systems may indeed be used to initiate adequate response of the medical staff, and effectively result in a greater sense of security by elderly clients. Telemonitoring systems for detecting falling incidents are often implemented by means of wearable sensors [29], [30]. An alternative approach is detecting falling incidents without human-attached sensors, for instance by means of vision systems [31], [32], (infrared) sensors that are placed in the home environment [33], [34], or acoustic measurement [35].

With regard to detecting wandering, numerous telemonitoring systems have been developed for detecting straying and wandering behaviour. Analogously to systems for detecting falling incidents, these systems may utilise wearable sensors [29], [36], [37], or may utilise sensors that are placed in the home environment [38], [39]. In case of the later, thresholding of sensory input within a predetermined timeframe may already provide a rudimentary form of monitoring. For instance, most elderly residents of assisted living residences may safely be allowed to wander off the premises during the night, while for particular residents the same behaviour should trigger an alarm.

\section{Monitoring activities of daily living}

Literature indicates on the importance of certain activities of daily living and their difficulty in measuring [5], [40]. Particularly, the literature concerns the basic activities of daily living (ADL) as defined by Katz [41]. As discussed in an overview article by Logan et al. [42], numerous systems have been proposed for gathering data on activities of daily living, e.g., systems based on accelerometers [43], [44], [30], [45], wrist worn RFID readers [46], vision systems [47], [48], [32], [49], localisation technology [50], and networks of relatively uncomplicated sensors [51], [52], [53], [54], [55], [56], such as infrared motion-sensors.

Once sensory data on the subject's activities of daily living has been gathered, the data is subsequently utilised by pattern recognition methods for classification of the activity that was observed [57], [46], [4], [56], [53], [58]. Results of the studies reveal that numerous activities of daily living may be classified with a generally high accuracy. Still, for application in practise, it remains of importance to consider the need and requirements for the domain of independently living elderly.

\section{Needs and requirements}

With regard to the needs for a telemonitoring system for independently living elderly, where needs are defined as something that is required or wanted, a study by Sponselee et al. [59] shows that health-related restraints that cause difficulties in daily life, increase the need for telemonitoring, and therefore increase the beneficial outcome effects of the technology for people. The same study shows that, in accordance with Maslow's pyramid, the most important functionality of the system is the alarm (with care support). Once the most important needs (safety \& care) are met, then higher order needs become more important (social contact). Analogously, research by Damodaran et al. [60] reveals that the key needs expressed by older people are: to live independently for a long as possible, to feel safe and secure, to be able to care for themselves and their homes, to enjoy a fulfilling life; and to enjoy life outside the home, as far as any impairments they have will allow. Recapitulating, literature indicates that the expressed needs generally refer to the following constructs: (1) general health, (2) housekeeping, (3) sleep, (4) personal hygiene, (5) mental wellbeing, (6) social interaction, (7) medicine intake, (8) eating and drinking, and (9) safety [61]. We will adopt these constructs in the remainder of our investigation.

With regard to the requirements, defined as prerequisites for fulfilling a particular needs, a study by Diaz et al. [62] concluded that elderly require (i) technology that is easy to learn and use, particularly were it to alter or replace a currently accepted method or device, (ii) new technology to be integrated in devices which they already master (as opposed to being introduced with a novel instrument), and (iii) technology that empowers their independence (as opposed to being dependent on assistive technology). The most important non-functional requirements for this domain are the use of non-wearable sensors, unobtrusiveness, ease of use, validity of information [63], durability [64], specificity, and reliability [65]. In addition, monitoring should be ubiquitous, so the monitored person would not need to remember to enable (or don) the equipment [66]. Requirements with regard to privacy, which are of evident concern to the present domain, pertain selective disclose, patient centricity, pseudonimity, and conditional deanonymization [67].

\section{INVENTORY OF NEEDS}

As noted in the introduction, there is a demand for an overview with respect to the needs of telemonitoring for the domain of independently living elderly. In the present section we report of this inventory of needs. First we discuss the method that was employed to establish the inventory (III-A).

Subsequently, in the subsections that follow, we report on results of interviews with health-care professionals (III-B), volunteer aids (III-C), residents of assisted living residences (III-D), and medical specialists (III-E).

\section{A. Method}

To establish an inventory of needs, we used semistructured in-depth interview techniques. For the interviews, 
we searched for participants from groups that will be involved most with the end use of a telemonitoring system, i.e., (1) health-care professionals (nurses), (2) volunteer aids, and (3) residents of assisted living residences. In addition, we consulted (4) medical specialists (e.g, geriatric specialists, physiotherapists, general practitioners) via an open, unstructured group discussion. The global setup, participants, and procedure of the interviews is discussed below.

1) Global setup: Interviewees from all target groups generally have little or no knowledge of telemonitoring systems and related techniques. As a result, an interviewee may have difficulty imagining the use and implications of telemonitoring for the domain of independently living elderly. Therefore, prior to the interviews, potential participants were invited to attend an information meeting, which introduced the concerning techniques using general phrasing and video material that showcased previously successful telemonitoring systems and ambient technology. Approximately ninety per cent of the later interviewees attended the information meeting. In case an interviewee did not attend the information meeting, the interviewer provided an ad hoc introduction to telemonitoring prior to the concerning interview. We utilised two distinct interview styles, namely (A) an open, informal style, and (B) a structured style with open questions, to stimulate the interviewees providing detailed opinions, experiences, and (implicated) descriptions of needs. The questions concern telemonitoring and the daily living / work routine, and are detailed on http://sander.landofsand.com/index.php? research.

2) Participants: A total of 36 individuals participated in the interviews (see Table I). The participants were acquired via contacts at two unrelated nursing institutes in the Amsterdam, The Netherlands region. Selection of participants took place via the following criteria. For interviews with the elderly: an elderly of age $65+$, living in an assisted living residence, no serious visual or hearing impairment, concentration span of approximate one hour. For interviews with volunteer aids, health-care professionals and medical specialists: a professional under contract for proving care for the abovely defined group of elderly.

3) Procedure: In the interviews, we utilised a list of open questions which implicitly refers to constructs that were found relevant according to the literature (see Subsection IID). We recall that these constructs are general health, housekeeping, sleep, personal hygiene, mental wellbeing, social interaction, medicine intake, eating and drinking, and safety. We discern between interviews that are performed in an open, informal style, and interviews performed in a structured style. The open interviews question informally, and in an openended fashion, the participant's conception on the benefits of telemonitoring. On the other hand, the structured interviews are not-open ended, and are focussed specifically on determining the particular group's need, c.q., need for specific information. Each interview style has distinct questions, of which a full list is available online. For analysis of the interviews, all interviews were recorded and transcribed into text. Utilising the transcribed answers, we determined whether or not the participants addressed the predetermined constructs in their answers. This was performed via (1) a syntactic matching of construct keywords, and synonyms therefore (e.g., hygiene, bathing, showering, etc.), and (2) a qualitative coding of themes, where the themes match the constructs that were suggested by the literature. Particularly, we determined if the information need is (or is not) met in the current situation, i.e., without the use of telemonitoring. In addition, we determined if, at present, information on a certain construct is currently administrated by a care taker or by the elderly.

\section{B. Interviews with health-care professionals}

Here we discuss the results of interviews with health-care professionals that operate in the domain of assisted living residences. As discussed in Subsection III-A, the interviews were carried out (1) in an open, informal style, as well as (2) in a structured style.

Open interviews with health-care professionals reveal that, in their view, monitoring techniques are relevant to the domain of assisted living residences, albeit in a limited context. This context is suggested (1) to concern foremost the monitoring of residents with a relatively high risk on immediate hospitalisation, and (2) to consider strictly the desire of residents for private and independent living. Interestingly, some health-care professionals put forward that additional monitoring may be required in the near future to relieve the work routine of care-takers, and, ideally, provide a higher quality of service for the residents. In particular, the majority of professionals envision an important role for preventive monitoring, i.e., monitoring the health and wellbeing of residents for the purpose of early detection and prevention of medical complications and hospitalisation. These initial findings suggest that pervasive healthcare technology in the domain of assisted living residences should be focussed foremost on detecting and responding to emergencies. Though additional monitoring may benefit directly elderly residents and healthcare professionals, we surmise that their acceptance is determined foremost by the ability to control and influence the technique, and by implication, the (careful) design of the pervasive technology.

Structured interviews with health-care professionals were focussed on the information need of this particular group. For the complete results, we refer the reader to Table II. The interviews reveal that the information need of health-care professionals concerns foremost indicators on the sufficiency of care provided to the elderly, in relation to potentially deteriorating health and wellbeing. That is, residents typically receive care with regard to personal hygiene and general health. Whether or not the residents require additional care, as indicatory to mental wellbeing, social interaction, and safety is of particular interest to the health-care professionals. To this end, they attempt to establish a conclusion on a resident's independence. In practice, the health-care professionals may be unable to establish such a conclusion reliably due to (1) non-periodic or non-existent contact with the 
TABLE I

DISTRIBUTION OF PARTICIPANTS.

\begin{tabular}{lcccc}
\hline Type of participant & $\#$ & Struct. int. & Open int. & Group discussion \\
\hline Health-care professionals & 10 & 7 & 5 & 0 \\
Volunteer aids & 10 & 10 & 0 & 0 \\
Elderly & 13 & 10 & 5 & 0 \\
Medical specialists & 3 & 0 & 0 & 1 \\
\hline Total & 36 & 27 & 10 & 1 \\
\hline
\end{tabular}

TABLE II

INFORMATION NEED OF HEALTH-CARE PROFESSIONALS. THE LEGEND IS AS FOLLOWS: ‘+' INDICATES THAT THE CARE-TAKER HAS GOOD ACCESS TO THIS INFORMATION, '-’ INDICATES THAT THE CARE TAKER HAS DIFFICULTY ACQUIRING THIS INFORMATION, 'P' INDICATES THAT THE INFORMATION IS ADMINISTRATED BY THE CARE-TAKER, AND ' Z' INDICATES THAT THE INFORMATION IS ADMINISTRATED BY THE ELDERLY.

\begin{tabular}{lccccccc}
\hline Category & \multicolumn{7}{c}{ Interviewed health-care professionals } \\
& $\mathrm{P} 1$ & $\mathrm{P} 2$ & $\mathrm{P} 3$ & $\mathrm{P} 4$ & $\mathrm{P} 5$ & $\mathrm{P} 6$ & $\mathrm{P} 7$ \\
\hline A. General health & $-/ \mathrm{P}$ & $-/+$ & $-/+$ & $+/-$ & + & $-/ \mathrm{P}$ & $-/ \mathrm{P}$ \\
B. Housekeeping & + & + & + & $+/-$ & + & $+/-$ & + \\
C. Sleep & $-/+$ & & $-/+$ & & + & $-/+$ & $+/-$ \\
D. Personal hygiene & $-/+$ & & + & + & $-/+$ & & + \\
E. Mental wellbeing & - & - & $-/+$ & & $-/+$ & $-/+$ & \\
F. Social interaction & - & - & - & $-/+$ & - & & $-/+$ \\
G. Medicine intake & $-/+/ \mathrm{P}$ & & & $-/ \mathrm{Z}$ & $\mathrm{Z}$ & + & $\mathrm{Z}$ \\
H. Eating/drinking & & + & $-/+$ & & $-/+$ & & \\
I. Safety & - & & - & $-/+$ & $-/+$ & - & - \\
\hline
\end{tabular}

residents, and (2) limited time for diagnosing during contact with residents. In numerous cases, unscheduled hospitalisation, and incidentally, imminent death, may have been avoided should accurate information on a resident's health and wellbeing have been available. This information may well be provided by a system for telemonitoring.

\section{Interviews with volunteer aids}

Here we discuss the results of interviews with volunteer aids that operate in the domain of assisted living residences. As discussed in Subsection III-A, the interviews were carried out in a structured style. The interviews with volunteer aids were focussed on the information need of this particular group. For the complete results, we refer the reader to Table III. The legend of the table is identical to that of Table II. A side-by-side comparison of the results is given in Table IV. It is discussed further in Section IV.

The interviews reveal that the information need of volunteer aids concerns foremost safety, relating to cases of falling incidents, fire, wandering, and intruder alert. In addition, the information need of volunteer aids was expressed to focus on deviations in sleep (e.g., leaving the bed), medicine intake (e.g., dosage, time of intake), eating/drinking (e.g., quantity, time of intake), general health (e.g., blood pressure, body temperature, signs of dementia), and social interaction (e.g., leaving the house). Particularly sleeping is of interest of this group, as elderly may require professional care once they wake up. Subsequently, the moment and amount of medicine intake and eating/drinking is generally decided and administrated by the elderly. As a result, volunteer aids may have incomplete or inaccurate insight into the actual health and wellbeing of the monitored elderly.

\section{Interviews with residents of assisted living residences}

Here we discuss the results of interviews with residents of assisted living residences, which were carried out (1) in an open, informal style, as well as (2) in a structured style (cf. Subsection III-A).

Open interviews with the residents indicate that they may accept telemonitoring to the extent that it is used for the purpose of detecting and responding to emergencies (e.g., falling incidents, wandering). However, the suggestion of additional forms of monitoring is received with opposition by the majority of the interviewees, even if it were to concern monitoring slowly developing medical conditions (e.g., cystitis). It is expressed that, considering the resident's desire for independent and relatively private living, telemonitoring should provide the residents with an ability to exert control on the monitoring system (e.g., location of sensors, access to data, moment of use).

Structured interviews with the residents reveal that the target group does not receive health care in a uniform manner. On the one hand, certain residents receive care up to six times per day (e.g., with bathing and dressing). On the other hand, certain residents receive no care whatsoever, and live strictly independent from caretakers. The implication of this context is discussed further in the next section. In addition, we note that residents express that they are often confronted by family, or caretakers, that are concerned about their general health and living conditions. Typically, 
TABLE III

INFORMATION NEED OF VOLUNTEER AIDS

\begin{tabular}{lccccccccccc}
\hline Category & \multicolumn{1}{l}{ Interviewed volunteer aids } & & & & & \\
& $\mathrm{V} 1$ & $\mathrm{~V} 2$ & $\mathrm{~V} 3$ & $\mathrm{~V} 4$ & $\mathrm{~V} 5$ & $\mathrm{~V} 6$ & $\mathrm{~V} 7$ & $\mathrm{~V} 8$ & $\mathrm{~V} 9$ & $\mathrm{~V} 10$ \\
\hline A. General health & $-/+$ & $\mathrm{P} /+$ & + & $\mathrm{P}$ & $\mathrm{P} /+$ & + & $\mathrm{P} /+/-$ & + & - & + \\
B. Housekeeping & + & + & $\mathrm{P}$ & $\mathrm{P}$ & + & + & $\mathrm{P} /+/-$ & $\mathrm{P} /+$ & $\mathrm{P} /+$ & + \\
C. Sleep & $\mathrm{P}$ & + & - & + & & + & + & - & + & - \\
D. Personal hygiene & $\mathrm{P}$ & $\mathrm{P} /+$ & $\mathrm{Z}$ & $\mathrm{P}$ & $\mathrm{P} /+$ & $\mathrm{Z} /+$ & - & $\mathrm{P} /+$ & $\mathrm{Z}$ & $+/ \mathrm{P}$ \\
E. Mental wellbeing & + & $\mathrm{P}$ & & + & & + & - & - & + & + \\
F. Social interaction & + & + & + & + & + & + & + & - & + & + \\
G. Medicine intake & + & + & - & - & - & $\mathrm{Z}$ & $\mathrm{Z}$ & $\mathrm{Z} /+$ & $\mathrm{Z} /-$ & + \\
H. Eating/drinking & + & + & - & + & + & - & + & - & + & $+/-$ \\
I. Safety & & & - & - & - & $+/-$ & + & - & - & \\
\hline
\end{tabular}

TABLE IV

INFORMATION NEED OF HEALTH-CARE PROFESSIONALS AND VOLUNTEER AIDS PER CATEGORY (TOTALS, SIDE-BY-SIDE).

(a) Health-care professionals

\begin{tabular}{|c|c|c|c|c|c|c|c|c|}
\hline Category & & 1 & 2 & 3 & 4 & 5 & 6 & 7 \\
\hline \multirow[t]{4}{*}{ General health } & - & $\mathrm{x}$ & $\mathrm{x}$ & $\mathrm{x}$ & $\mathrm{x}$ & $\mathrm{x}$ & $\mathrm{x}$ & \\
\hline & + & $\mathrm{x}$ & $\mathrm{x}$ & $\mathrm{x}$ & $\mathrm{x}$ & & & \\
\hline & $\mathrm{P}$ & $\mathrm{x}$ & $\mathrm{x}$ & $\mathrm{x}$ & & & & \\
\hline & $\mathrm{Z}$ & & & & & & & \\
\hline \multirow[t]{4}{*}{ Housekeeping } & - & $\mathrm{x}$ & $\mathrm{x}$ & & & & & \\
\hline & + & $\mathrm{x}$ & $\mathrm{x}$ & $\mathrm{x}$ & $\mathrm{x}$ & $\mathrm{x}$ & $\mathrm{X}$ & $\mathrm{X}$ \\
\hline & $\mathrm{P}$ & & & & & & & \\
\hline & $\mathrm{Z}$ & & & & & & & \\
\hline \multirow[t]{4}{*}{ Sleep } & - & $\mathrm{x}$ & $\mathrm{x}$ & $\mathrm{x}$ & $\mathrm{x}$ & & & \\
\hline & + & $\mathrm{x}$ & $\mathrm{x}$ & $\mathrm{x}$ & $\mathrm{x}$ & $\mathrm{x}$ & & \\
\hline & $\mathrm{P}$ & & & & & & & \\
\hline & $\mathrm{Z}$ & & & & & & & \\
\hline \multirow[t]{4}{*}{ Personal hygiene } & - & $\mathrm{x}$ & $\mathrm{x}$ & & & & & \\
\hline & + & $\mathrm{x}$ & $\mathrm{x}$ & $\mathrm{x}$ & $\mathrm{x}$ & $\mathrm{x}$ & & \\
\hline & $\mathrm{P}$ & & & & & & & \\
\hline & $\mathrm{Z}$ & & & & & & & \\
\hline \multirow[t]{4}{*}{ Mental wellbeing } & - & $\mathrm{x}$ & $\mathrm{x}$ & $\mathrm{x}$ & $\mathrm{x}$ & $\mathrm{x}$ & & \\
\hline & + & $\mathrm{x}$ & $\mathrm{x}$ & $\mathrm{x}$ & & & & \\
\hline & $\mathrm{P}$ & & & & & & & \\
\hline & $\mathrm{Z}$ & & & & & & & \\
\hline \multirow[t]{4}{*}{ Social interaction } & - & $\mathrm{x}$ & $\mathrm{x}$ & $\mathrm{x}$ & $\mathrm{x}$ & $\mathrm{x}$ & $\mathrm{x}$ & \\
\hline & + & $\mathrm{X}$ & $\mathrm{X}$ & & & & & \\
\hline & $\mathrm{P}$ & & & & & & & \\
\hline & $\mathrm{Z}$ & & & & & & & \\
\hline \multirow[t]{4}{*}{ Medicine intake } & - & $\mathrm{x}$ & $\mathrm{x}$ & & & & & \\
\hline & + & $\mathrm{x}$ & $\mathrm{x}$ & & & & & \\
\hline & $\mathrm{P}$ & $\mathrm{X}$ & & & & & & \\
\hline & $\mathrm{Z}$ & $\mathrm{x}$ & $\mathrm{x}$ & $\mathrm{x}$ & & & & \\
\hline \multirow[t]{4}{*}{ Eating/drinking } & - & $\mathrm{x}$ & $\mathrm{x}$ & & & & & \\
\hline & + & $\mathrm{X}$ & $\mathrm{X}$ & $\mathrm{X}$ & & & & \\
\hline & $\mathrm{P}$ & & & & & & & \\
\hline & $\mathrm{Z}$ & & & & & & & \\
\hline \multirow[t]{4}{*}{ Safety } & - & $\mathrm{X}$ & $\mathrm{X}$ & $\mathrm{x}$ & $\mathrm{x}$ & $\mathrm{x}$ & $\mathrm{x}$ & \\
\hline & + & $\mathrm{X}$ & $\mathrm{X}$ & & & & & \\
\hline & $\mathrm{P}$ & & & & & & & \\
\hline & Z & & & & & & & \\
\hline
\end{tabular}

(b) Volunteer aids

\begin{tabular}{|c|c|c|c|c|c|c|c|c|c|c|c|}
\hline Category & & 1 & 2 & 3 & 4 & 5 & 6 & 7 & 8 & 9 & 10 \\
\hline \multirow[t]{4}{*}{ General health } & - & $\mathrm{x}$ & $\mathrm{x}$ & $\mathrm{X}$ & & & & & & & \\
\hline & + & $\mathrm{x}$ & $\mathrm{x}$ & $\mathrm{X}$ & $\mathrm{x}$ & $\mathrm{x}$ & $\mathrm{x}$ & $\mathrm{x}$ & $\mathrm{x}$ & & \\
\hline & $P$ & $\mathrm{X}$ & $\mathrm{X}$ & $\mathrm{X}$ & $\mathrm{X}$ & & & & & & \\
\hline & $\mathrm{Z}$ & & & & & & & & & & \\
\hline \multirow[t]{4}{*}{ Housekeeping } & - & $\mathrm{x}$ & & & & & & & & & \\
\hline & + & $\mathrm{x}$ & $\mathrm{x}$ & $\mathrm{X}$ & $\mathrm{x}$ & $\mathrm{x}$ & $\mathrm{x}$ & $\mathrm{x}$ & $\mathrm{x}$ & & \\
\hline & $P$ & $\mathrm{X}$ & $X$ & X & $\mathrm{X}$ & X & & & & & \\
\hline & $\mathrm{Z}$ & & & & & & & & & & \\
\hline \multirow[t]{4}{*}{ Sleep } & - & $\mathrm{x}$ & $\mathrm{x}$ & $\mathrm{x}$ & & & & & & & \\
\hline & + & $\mathrm{x}$ & $\mathrm{x}$ & $\mathrm{X}$ & $\mathrm{x}$ & $\mathrm{x}$ & & & & & \\
\hline & $\mathrm{P}$ & $\mathrm{x}$ & & & & & & & & & \\
\hline & $\mathrm{Z}$ & & & & & & & & & & \\
\hline \multirow[t]{4}{*}{ Personal hygiene } & - & $\mathrm{x}$ & & & & & & & & & \\
\hline & + & $\mathrm{x}$ & $\mathrm{x}$ & $\mathrm{X}$ & $\mathrm{x}$ & $\mathrm{x}$ & & & & & \\
\hline & $P$ & $\mathrm{X}$ & $X$ & X & $\mathrm{X}$ & X & 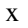 & & & & \\
\hline & Z & $\mathrm{x}$ & $\mathrm{x}$ & $\mathrm{X}$ & & & & & & & \\
\hline \multirow[t]{4}{*}{ Mental wellbeing } & - & $\mathrm{x}$ & $\mathrm{x}$ & & & & & & & & \\
\hline & + & $\mathrm{X}$ & $X$ & $\mathrm{X}$ & $\mathrm{X}$ & X & & & & & \\
\hline & $\mathrm{P}$ & $\mathrm{x}$ & & & & & & & & & \\
\hline & $\mathrm{Z}$ & & & & & & & & & & \\
\hline \multirow[t]{4}{*}{ Social interaction } & - & $\mathrm{x}$ & & & & & & & & & \\
\hline & + & $\mathrm{x}$ & $\mathrm{x}$ & $\mathrm{x}$ & $\mathrm{x}$ & $\mathrm{x}$ & $\mathrm{x}$ & $\mathrm{x}$ & $\mathrm{x}$ & $\mathrm{x}$ & \\
\hline & $\mathrm{P}$ & & & & & & & & & & \\
\hline & $\mathrm{Z}$ & & & & & & & & & & \\
\hline \multirow[t]{4}{*}{ Medicine intake } & - & $\mathrm{x}$ & $\mathrm{X}$ & $\mathrm{X}$ & $\mathrm{x}$ & & & & & & \\
\hline & + & $\mathrm{x}$ & $\mathrm{x}$ & $\mathrm{x}$ & $\mathrm{x}$ & & & & & & \\
\hline & $\mathrm{P}$ & & & & & & & & & & \\
\hline & $\mathrm{Z}$ & $\mathrm{x}$ & $\mathrm{x}$ & $\mathrm{x}$ & $\mathrm{x}$ & & & & & & \\
\hline \multirow[t]{4}{*}{ Eating/drinking } & - & $\mathrm{x}$ & $\mathrm{x}$ & $\mathrm{x}$ & $\mathrm{x}$ & & & & & & \\
\hline & + & $\mathrm{x}$ & $\mathrm{x}$ & $\mathrm{x}$ & $\mathrm{x}$ & $\mathrm{x}$ & $\mathrm{x}$ & $\mathrm{x}$ & & & \\
\hline & $\mathrm{P}$ & & & & & & & & & & \\
\hline & Z & & & & & & & & & & \\
\hline \multirow[t]{3}{*}{ Safety } & - & $\mathrm{x}$ & $\mathrm{x}$ & $\mathrm{x}$ & $\mathrm{x}$ & $\mathrm{x}$ & $\mathrm{x}$ & & & & \\
\hline & + & $\mathrm{x}$ & $\mathrm{x}$ & & & & & & & & \\
\hline & $\begin{array}{l}\mathrm{P} \\
\mathrm{Z}\end{array}$ & & & & & & & & & & \\
\hline
\end{tabular}

the concerns relate to potential incidents and the adequate response thereon, and whether or not the provided care is still sufficient for a resident's present situation. We surmise that, for a large extent, these concerns may not have risen had specific information been available on the health and wellbeing of the residents. Generally, as the interviewees 
pointed out, social commitment amongst the residents of assisted living residences is relatively low. In this regard, we note that telemonitoring may also have application, for instance as a means to enhance the sense of security within a network of relatively isolatedly-living elderly.

\section{E. Discussion with medical specialists}

Here we discuss the results of an open, unstructured group discussion with medical specialists (cf. Subsection III-A). The medical specialists indicate that they deem telemonitoring particularly relevant for monitoring (1) inactivity, (2) selfneglect, and (3) loneliness. With regard to these three points of attention, the specialist suggest numerous measurable indicators. That is, for inactivity, measuring physical movement is suggested (e.g., the distance covered by walking indoors, the number of times that an individual leaves the house). For self-neglect, measuring toileting, bathing, self medication, doing groceries, dressing, and feeding is suggested. We note that these suggestions reflect for a large extent the basic activities of daily living (ADL) as defined by Katz [41], i.e., bathing, dressing, toileting, transferring, continence, and feeding. For loneliness, measuring the number of social visits is suggested, and the number of times that an individual leaves the house. Moreover, the medical specialists, in light of anticipated acceptance by caretakers, reason against monitoring systems that are focussed solely on providing caretakers with an automatically generated diagnosis of a client's health and wellbeing. Instead, the specialists suggest a focus on signaling deviations and trends in behavioural patterns, to ensure that the caretakers can respond timely and adequately to alarming situations in the present, and in the long term.

In addition, the specialists note that the group of elderly people that may benefit most from telemonitoring techniques, are those that currently receive little to no monitoring by means of conventional health care. Yet, numerous of these elderly people consciously refrain from utilising health care services. Analogously, one may expect that services provided by telemonitoring techniques will be declined by this particular group. Inversely, one may also expect elderly people to adopt telemonitoring techniques precisely because it empowers them to remain independent, in control, and without the need for unwanted visits of caretakers [68].

\section{Setting the Requirements}

In this section we set the requirements for a telemonitoring system for independently living elderly. First we provide (A) a general discussion of the results of the interviews. Subsequently, we discuss (B) how to map the interview results to requirements for a telemonitoring system for the target domain.

\section{A. General discussion}

In a comparison of the interview results of health-care professionals and volunteer aids, we observe note several interesting difference in the results (see Table IV). That is, health-care professionals have difficulty assessing the general health, mental wellbeing, and social interaction of elderly, whereas this seems not to be an issue for volunteer aids. An explanation of this phenomenon may be that due to better medical education of the health-care professionals, they are more aware and knowledgeable on the insufficiency on their diagnoses. Where, on the other hand, volunteer aids may draw conclusions on the health and wellbeing of the elderly with less restraint.

In addition, we note that independently living elderly do not receive care in a uniform manner. Some individuals, in fact, reside in an assisted living residence, yet have no contact with health-care professionals whatsoever. Though the difference in received care within the target domain is of natural concern to placement and marketing of a telemonitoring product (which falls outside the scope of our research), we note particularly that individuals who may benefit most from a telemonitoring system, are those individuals who at present reside independently from care, and live relatively isolated in terms of social contacts. In this regard, the biggest challenge for telemonitoring may not be technical in nature, but rather a matter of creating conditions for acceptance by the elderly. We surmise that the perceived ability to empowerment (as opposed to interference), may contribute greatly to final acceptance, and by implication, the effectiveness in practise of a telemonitoring system. Now that the issues that came forth have been discussed, we continue by mapping the interview results to requirements.

\section{B. Mapping the interview results to requirements}

Here we discuss how to map the interview results to requirements for a telemonitoring system for the domain of independently living elderly. In our discussion, we concentrate on the focus the system (B.1), its functionality (B.2), and its form (B.3).

1) Focus: In accordance with work by Sponselee et al. [59], interviews with both residents of assisted living residences and volunteer aids reveal that their information need concerns foremost safety, typically with regard to care response on emergencies (e.g., falling incidents, wandering). However, interviews with health-care professionals and medical specialists reveal that their information need concerns indicators on the elderly's dependence on care (e.g., inactivity, self-neglect, loneliness). As prioritising monitoring the dependence on care over monitoring safety may substantially hamper acceptance by elderly, or inversely, utilisation of the telemonitoring system by health-care professionals, we would like to argue that as a requirement for the domain of independently living elderly, the focus of a telemonitoring system should lie both on monitoring safety, as well as on monitoring independence.

2) Functionality: With regard to functionality, we note that a telemonitoring system focussed on safety and dependence monitoring may take distinct directions ( $c f$. Section II). However, as literature indicates the importance of providing technology that empowers elderly to remain independent from care [68], we would like to argue for a monitoring system with as functionality a semi-automatic emergency 
response. That is, the trigger to emergency response should always be (1) raised by the elderly, or (2) confirmed by the elderly, albeit implicitly in case of unconsciousness. A potentially powerful implementation in this regard, are sensor networks that are connected to an intelligent voice response system. Functionally, monitoring independence may be implemented via relatively simple measures (e.g., decline of movement speed in a certain location), to relatively complex measure (e.g., classification of activity patterns, and deviations therein). We recommend researchers to establish precisely which of the numerous measures with regard to independence they are interested in, and on this basis adopt available technology accordingly.

3) Form: In accordance with literature discussed in Subsection II-D, requirements with regard to the form of the telemonitoring system point foremost to the use of nonwearable sensors, unobtrusiveness [63], durability [64], and reliability [65]. In addition, monitoring should be ubiquitous, so the monitored person would not need to remember to enable (or don) the equipment [66]. Requirements with regard to privacy are investigated in detail by Layouni et al. [67]. Considering the requirements mentioned above, we would like to argue for ubiquitous telemonitoring that is based on simple sensors (e.g., reed switches, motion sensors) that are placed unobtrusively in the home environment (e.g., without extensive and visible wiring). Evidently, the selected sensors need to be durable with regard to battery life, and reliable with regard to continuous availability of sensor data, and noise therein.

\section{COnClusions And Future Work}

In this paper we investigated the precise focus required of a telemonitoring system for the domain of independently living elderly. Particularly, we investigated (1) the needs of telemonitoring for this particular domain, and (2) the requirements for such a telemonitoring system. For our investigation, we performed an extensive study of the literature, as well as performed interviews with 36 individuals active in the field. As a result, we established numerous needs to be considered, being foremost information need on safety, with regard to care response on emergencies (e.g., falling incidents, wandering), as well information need on dependence on care, with regard to inactivity, self-neglect and loneliness. Subsequently, we established numerous requirements to be addressed, being foremost the use of non-wearable sensors, unobtrusiveness, durability, reliability, privacy, and ubiquitousness. In our discussion of the requirements, we detailed specifically the topics of focus, functionality, and form of a telemonitoring system for this domain.

For future work, we will investigate the acceptance by elderly, and utilisation by health-care professionals, together with its benefits, of a telemonitoring system that in its design considers the needs and requirements that were established.

\section{ACKNOWLEDGEMENTS}

The research reported in this paper was supported by the SIA project 'Smart Systems for Smart Services' and the
Pieken in de Delta project 'Zorgen voor Morgen'.

\section{REFERENCES}

[1] S. Meystre, "The current state of telemonitoring: a comment on the literature," Telemedicine Journal \& e-Health, vol. 11, no. 1, pp. 63-69, 2005.

[2] M. Cordisco, A. Beniaminovitz, K. Hammond, and D. Mancini, "Use of telemonitoring to decrease the rate of hospitalization in patients with severe congestive heart failure," The American journal of cardiology, vol. 84, no. 7, pp. 860-862, 1999.

[3] J. Cohen, "Human population: the next half century," Science, vol. 302, no. 5648, p. 1172, 2003.

[4] D. Wilson and C. Atkeson, "Simultaneous tracking and activity recognition (STAR) using many anonymous, binary sensors," Pervasive Computing, pp. 62-79, 2005.

[5] D. Wilson, S. Consolvo, K. Fishkin, and M. Philipose, "In-home assessment of the activities of daily living of the elderly," in Extended Abstracts of CHI 2005: Workshops-HCI Challenges in Health Assessment, 2005.

[6] T. van Kasteren and B. Kröse, "Bayesian activity recognition in residence for elders," Intelligent Environments, pp. 209-212, 2007.

[7] M. Marmot and R. Wilkinson, Social determinants of health. Oxford University Press Oxford, 2006.

[8] S. Lusignan, A. Althans, S. Wells, P. Johnson, M. Vandenburg, and J. Robinson, "A pilot study of radiotelemetry for continuous cardiopulmonary monitoring of patients at home," Journal of Telemedicine and Telecare, vol. 6, no. Supplement 1, p. 119, 2000.

[9] P. Johnson and D. Andrews, "Remote continuous physiological monitoring in the home." Journal of telemedicine and telecare, vol. 2, no. 2 , p. 107, 1996.

[10] M. Quemere, J. Boutroy, J. Fresson, F. Abel, and P. BarbarinoMonnier, "Fetal home telemonitoring: the Nancy experience from 1992-1997. Analysis of 12649 recordings," Journal de gynécologie, obstétrique et biologie de la reproduction, vol. 29, no. 6, p. 571, 2000.

[11] R. Naef 3rd, K. Perry Jr, E. Magann, B. McLaughlin, S. Chauhan, and J. Morrison, "Home blood pressure monitoring for pregnant patients with hypertension." Journal of perinatology: official journal of the California Perinatal Association, vol. 18, no. 3, p. 226, 1998.

[12] N. Artinian, O. Washington, and T. Templin, "Effects of home telemonitoring and community-based monitoring on blood pressure control in urban African Americans: A pilot study," Heart \& Lung: The Journal of Acute and Critical Care, vol. 30, no. 3, pp. 191-199, 2001.

[13] S. Barro, J. Presedo, D. Castro, M. Fernandez-Delgado, S. Fraga, M. Lama, and J. Vila, "Intelligent telemonitoring of critical-care patients," IEEE Engineering in medicine and biology magazine, vol. 18, no. 4, pp. 80-88, 1999.

[14] E. Jovanov, D. Raskovic, J. Price, A. Krishnamurthy, J. Chapman, and A. Moore, "Patient monitoring using personal area networks of wireless intelligent sensors," Biomedical Sciences Instrumentation, vol. 37, pp. 373-378, 2001.

[15] V. Barbaro, P. Bartolini, and R. Bernarducci, "A portable unit for remote monitoring of pacemaker patients," Journal of telemedicine and telecare, vol. 3, no. 2, p. 96, 1997.

[16] J. Vincent, D. Cavitt, and P. Karpawich, "Diagnostic and cost effectiveness of telemonitoring the pediatric pacemaker patient," Pediatric cardiology, vol. 18, no. 2, pp. 86-90, 1997.

[17] J. Belmont, L. Mattioli, K. Goertz, R. Ardinger JR, and C. Thomas, "Evaluation of remote stethoscopy for pediatric telecardiology," Telemedicine Journal, vol. 1, no. 2, pp. 133-149, 1995.

[18] A. Nicogossian, D. Pober, and S. Roy, "Evolution of telemedicine in the space program and earth applications," Telemedicine Journal and e-Health, vol. 7, no. 1, pp. 1-15, 2001.

[19] E. Gómez, M. Hernando, A. Garcia, F. Del Pozo, J. Cermeño, R. Corcoy, E. Brugues, and A. De Leiva, "Telemedicine as a tool for intensive management of diabetes: the DIABTel experience," Computer Methods and Programs in Biomedicine, vol. 69, no. 2, pp. 163-177, 2002.

[20] R. Satava, P. Angood, B. Harnett, C. Macedonia, and R. Merrell, "The physiologic cipher at altitude: telemedicine and real-time monitoring of climbers on Mount Everest," Telemedicine Journal and e-Health, vol. 6, no. 3, pp. 303-313, 2000.

[21] J. Calagan, "Remote Interactive Monitoring of Patients on Anticoagulant Therapy to Improve Outcome and Avoid Complications," Walter Reed Army Medical Centre Washington DC, Tech. Rep., 2001. 
[22] J. Finkelstein, M. Cabrera, and G. Hripcsak, "Internet-based home asthma telemonitoring: can patients handle the technology?" Chest Chicago, vol. 117, no. 1, pp. 148-155, 2000.

[23] D. Hallauer and C. Bolliger, "Comparison of a New Desktop Spirometer (Diagnosa $\AA)$ with a Laboratory Spirometer," Respiration, vol. 68, pp. 400-404, 2001.

[24] T. Oohashi, N. Kawai, M. Honda, S. Nakamura, M. Morimoto, E. Nishina, and T. Maekawa, "Electroencephalographic measurement of possession trance in the field," Clinical Neurophysiology, vol. 113, no. 3, pp. 435-445, 2002.

[25] M. Field and J. Grigsby, "Telemedicine and remote patient monitoring," Jama, vol. 288, no. 4, p. 423, 2002.

[26] N. Güler and E. Übeyli, "Theory and applications of biotelemetry," Journal of Medical Systems, vol. 26, no. 2, pp. 159-178, 2002.

[27] H. Edelberg, E. Shallenberger, J. Hausdorff, and J. Wei, "One-year follow-up of medication management capacity in highly functioning older adults," Journals of Gerontology Series A: Biological and Medical Sciences, vol. 55, no. 10, p. 550, 2000.

[28] K. Horton, R. RN, and P. RNT, "Falls in older people: The place of telemonitoring in rehabilitation." Journal of rehabilitation research and development, vol. 45, no. 8, p. 1183, 2008.

[29] J. Chen, K. Kwong, D. Chang, J. Luk, and R. Bajcsy, "Wearable sensors for reliable fall detection," in Engineering in Medicine and Biology Society, 2005. IEEE-EMBS 2005. 27th Annual International Conference of the, 2005, pp. 3551-3554.

[30] A. Bourke, J. O'Brien, and G. Lyons, "Evaluation of a thresholdbased tri-axial accelerometer fall detection algorithm," Gait \& posture, vol. 26, no. 2, pp. 194-199, 2007.

[31] C. Tang, Y. Hung, and Z. Chen, "Automatic detection and tracking of human heads using an active stereo vision system," Computer VisionACCV'98, pp. 632-639, 1998.

[32] H. Nait-Charif and S. McKenna, "Activity summarisation and fall detection in a supportive home environment," in Pattern Recognition, 2004. ICPR 2004. Proceedings of the 17th International Conference on, vol. 4, 2004.

[33] K. Doughty and C. Steele, "The use of telecare and community equipment to improve joint working across health and social care," Journal of Assistive Technologies, vol. 3, no. 4, pp. 36-43, 2009.

[34] A. Sixsmith and N. Johnson, "A smart sensor to detect the falls of the elderly," IEEE Pervasive Computing, vol. 3, no. 2, pp. 42-47, 2004.

[35] M. Popescu, S. Coupland, and S. Date, "A fuzzy logic system for acoustic fall detection," 2008.

[36] U. Maurer, A. Rowe, A. Smailagic, and D. Siewiorek, "eWatch: a wearable sensor and notification platform," in Wearable and Implantable Body Sensor Networks, 2006. BSN 2006. International Workshop on, 2006, p. 4.

[37] J. Yin, Q. Yang, and J. Pan, "Sensor-based abnormal human-activity detection," IEEE Transactions on Knowledge and Data Engineering, vol. 20, no. 8, pp. 1082-1090, 2008.

[38] J. Cabero, F. De la Torre, A. Sanchez, and I. Arizaga, "Indoor people tracking based on dynamic weighted multidimensional scaling," in Proceedings of the 10th ACM Symposium on Modeling, analysis, and simulation of wireless and mobile systems. ACM, 2007, p. 335.

[39] C. Huang, Y. Tseng, and H. Wu, "Distributed protocols for ensuring both coverage and connectivity of a wireless sensor network," ACM Transactions on Sensor Networks (TOSN), vol. 3, no. 1, p. 5, 2007.

[40] F. M. Ligion, "Care project: ADL information desired by caregivers," Master's thesis, Universiteit van Amsterdam, The Netherlands, March 2008.

[41] S. Katz, T. Downs, H. Cash, and R. Grotz, "Progress in development of the index of ADL," The Gerontologist, vol. 10, no. 1 Part 1, p. 20, 1970.

[42] B. Logan, J. Healey, M. Philipose, E. M. Tapia, and S. S. Intille, "A long-term evaluation of sensing modalities for activity recognition," in Proc. of Ubicomp07, 2007, pp. 483-500.

[43] P. Caselli, "Monitoring of daily living activities in a perspective of telerehabilitation," Ph.D. dissertation, Università di Bologna, 2007.

[44] J. Lester, T. Choudhury, N. Kern, G. Borriello, and B. Hannaford, "A hybrid discriminative/generative approach for modeling human activities," in In Proc. of the International Joint Conference on Artificial Intelligence (IJCAI, 2005, pp. 766-772.

[45] M. Marzencki, B. Hung, P. Lin, Y. Huang, T. Cho, Y. Chuo, and B. Kaminska, "Wireless sensor network for context-aware health and activity monitoring," Gerontechnology, vol. 9, no. 2, pp. 102-103, 2010.
[46] D. J. Patterson, D. Fox, and H. Kautz, "Fine-grained activity recognition by aggregating abstract object usage," in Ninth IEEE International Symposium on Wearable Computers, 2005, pp. 44-51.

[47] D. Gavrila, "The Visual Analysis of Human Movement: A Survey," Computer Vision and Image Understanding, vol. 73, no. 1, pp. 82-98, 1999.

[48] T. B. Moeslund, A. Hilton, and V. Krüger, "A survey of advances in vision-based human motion capture and analysis," Comput. Vis. Image Underst., vol. 104, no. 2, pp. 90-126, 2006.

[49] N. Zouba, F. Bremond, A. Anfosso, M. Thonnat, E. Pascual, and O. Guerin, "Monitoring elderly activities at home," Gerontechnology, vol. 9, no. 2, p. 263, 2010.

[50] C. Crump, "Mobile monitoring to support independence and safety," Gerontechnology, vol. 9, no. 2, pp. 157-158, 2010.

[51] V. Rialle, J.-B. Lamy, N. Noury, and L. Bajolle, "Telemonitoring of patients at home: a software agent approach," Computer Methods and Programs in Biomedicine, vol. 72, no. 3, pp. 257-268, 2003.

[52] D. H. Wilson, "Assistive intelligent environments for automatic in-home health monitoring," Ph.D. dissertation, Robotics Institute, Carnegie Mellon University, Pittsburgh, PA, September 2005.

[53] G. Alexander, C. Galambos, M. Skubic, and S. Wang, "Density map visualisation as a tool to monitor activity levels of older adults," Gerontechnology, vol. 9, no. 2, p. 186, 2010.

[54] T. Hayes, "Unobtrusive assessment of activity patterns associated with mild cognitive impairment," Gerontechnology, vol. 9, no. 2, pp. 122123, 2010.

[55] D. Mack, "Passive monitoring to meet individual health and safety needs," Gerontechnology, vol. 9, no. 2, pp. 158-159, 2010.

[56] T. van Kasteren, G. Englebienne, and B. Kröse, "An activity monitoring system for elderly care using generative and discriminative models," Personal and Ubiquitous Computing, pp. 1-10, 2010, special Issue on Pervasive Technologies for Assistive Environments.

[57] T. Duong, H. Bui, D. Phung, and S. Venkatesh, "Activity recognition and abnormality detection with the switching hidden semi-markov model," in IEEE Computer Society Conference on Computer Vision and Pattern Recognition, 2005. CVPR 2005, vol. 1, 2005.

[58] M. Floeck and L. Litz, "Advanced algorithms for activity monitoring among seniors living single in their private homes," Gerontechnology, vol. 9, no. 2, p. 211, 2010.

[59] A. Sponselee, B. Schouten, and D. Bouwhuis, "Telecare for elderly users: Needs and benefits," Gerontechnology, vol. 9, no. 2, p. 249, 2010.

[60] L. Damodaran and C. Olphert, "Assisted living technologies: Users' needs and challenges for successful uptake," Gerontechnology, vol. 9, no. 2, p. 249, 2010

[61] R. Morsch, "Onderzoek naar de informatiebehoefte van mantelzorgers," Master's thesis, Universiteit van Amsterdam, The Netherlands, 2010.

[62] U. Diaz, A. Garciá, and E. Urdaneta, "What elderly users do not want from technology: A qualitative approach," Gerontechnology, vol. 9, no. 2, p. 210, 2010.

[63] M. Brul, R. Huis in 't Veld, J. v. Gemert-Pijnen, C. Willems, and H. Hermens, "Designing a telecare system for caregivers: A usercentered approach using scenarios," Gerontechnology, vol. 9, no. 2, pp. 175-176, 2010.

[64] I. Korhonen, J. Parkka, and M. Van Gils, "Health monitoring in the home of the future," IEEE Engineering in Medicine and Biology Magazine, vol. 22, no. 3, pp. 66-73, 2003.

[65] D. Scherr, P. Kastner, A. Kollmann, A. Hallas, J. Auer, H. Krappinger, H. Schuchlenz, G. Stark, W. Grander, G. Jakl, et al., "Effect of homebased telemonitoring using mobile phone technology on the outcome of heart failure patients after an episode of acute decompensation: randomized controlled trial," 2009.

[66] C. Scanaill, S. Carew, P. Barralon, N. Noury, D. Lyons, and G. Lyons, "A review of approaches to mobility telemonitoring of the elderly in their living environment," Annals of Biomedical Engineering, vol. 34, no. 4, pp. 547-563, 2006.

[67] M. Layouni, K. Verslype, M. Sandikkaya, B. De Decker, and H. Vangheluwe, "Privacy-Preserving Telemonitoring for eHealth," Data and Applications Security XXIII, pp. 95-110, 2009.

[68] G. Paré, M. Jaana, and C. Sicotte, "Systematic review of home telemonitoring for chronic diseases: the evidence base," Journal of the American Medical Informatics Association, vol. 14, no. 3, p. 269, 2007. 